\title{
Transfer of upper trapezius with clavicular segment for restoration of shoulder movements following injury to the brachial plexus
}

\author{
Neeraj Kant Agrawal \\ Department of Plastic Surgery, Institute of Medical Sciences, Banaras Hindu University, Varanasi 221005, Uttar Pradesh, India.
}

Address for correspondence: Dr. Neeraj Kant Agrawal, Department of Plastic Surgery, Institute of Medical Sciences, Banaras Hindu University, Varanasi 221005, Uttar Pradesh, India. E-mail: nkagrawal_vns@rediffmail.com

\begin{abstract}
Aim: Most brachial plexus palsies occur following high-velocity trauma. The shoulder joint is a large proximal joint which influences the motion of the hand. Transfer of the trapezius muscle is an effective alternative for palsy of the deltoid and supraspinatus muscles. Methods: Between 2009 and 2014, 32 patients were treated with modified trapezius muscle transfer in which only the descending fibers along with their attachment to the lateral third of clavicle were used. The clavicle was fixed to the anterolateral surface of the humerus by cancellous screws. The arm was immobilized for 6 weeks. Results: All the 32 patients had improved function with stability of the shoulder. The average increase in active abduction was from $7.5^{\circ}$ (range: $0^{\circ}-30^{\circ}$ ) to $85^{\circ}$ (range: $45^{\circ}-140^{\circ}$ ), and the mean forward flexion increased from $5.63^{\circ}$ (range: $0^{\circ}-15^{\circ}$ ) to $55.2^{\circ}$ (range: $40^{\circ}-90^{\circ}$ ) after a mean follow-up of 8.25 months. Twenty-four of the 32 patients rated the result as good to excellent and were satisfied with the improvement in stability and function. Fifty nine point thirty eight percent patients had Medical Research Council Muscle power 4 after the surgery. Conclusion: Transfer of the upper trapezius muscle with a segment of the clavicle segment for a flail shoulder can provide satisfactory function and stability with fewer complications.
\end{abstract}

Key words:

Brachial plexus, shoulder arthrodesis, trapezius transfer

\section{INTRODUCTION}

Restoration of shoulder stability in posttraumatic plexopathy patients is critical in the preservation of distal function. ${ }^{[1]}$ However, the complexity of management can be frustrating for both patient and surgeon. Primary surgery involves nerve repair, grafting and transfer techniques. Failed operations for the shoulder may require secondary procedures in the form of microneurovascular free-functioning muscle transfer, ${ }^{[2]}$ tendon transfers and

\begin{tabular}{|l|l|}
\hline \multicolumn{2}{|c|}{ Access this article online } \\
\hline Quick Response Code: & Website: \\
\hline & www.parjournal.net \\
\cline { 2 - 3 } & \\
\hline & \\
\hline
\end{tabular}

arthrodesis to improve or restore function. A clear understanding of shoulder anatomy and biomechanics is of paramount importance when using adjacent muscles for transfer. ${ }^{[3]}$ Options for transfer include the trapezius, ${ }^{[4,5]}$ pectoralis major ${ }^{[6]}$ and teres major, latissimus $\operatorname{dors}^{[2]}$ and combined biceps and triceps muscles.

The trapezius muscle has been extensively studied and used. Transfer of the trapezius insertion was first described

This is an open access article distributed under the terms of the Creative Commons Attribution-NonCommercial-ShareAlike 3.0 License, which allows others to remix, tweak, and build upon the work non-commercially, as long as the author is credited and the new creations are licensed under the identical terms.

For reprints contact: reprints@medknow.com

How to cite this article: Agrawal NK. Transfer of upper trapezius with clavicular segment for restoration of shoulder movements following injury to the brachial plexus. Plast Aesthet Res 2015;2:346-9.

Received: 30-05-2015; Accepted: 06-09-2015 
by Mayer ${ }^{[7]}$ who used a fascia lata graft, albeit with poor results. Bateman's ${ }^{[4]}$ procedure involved resection of part of the spine of the scapula with the trapezius. This procedure was further modified by Saha, ${ }^{[5]}$ who also mobilized the upper and middle segments of the trapezius muscle.

The trapezius has three functional segments, consisting of a descending segment which supports the weight of the arm; a transverse segment which retracts the scapula; and an ascending segment which medially rotates and depresses the scapula. Along with the levator scapulae and the serratus anterior, the middle and lower fibers of the trapezius muscle provide shoulder stability for arm movements and for that reason should be spared. The descending fibers which attach to the posterior aspect of the lateral third of the clavicle can be safely used. A more anterolateral fixation on the humerus is expected to abduct and forward flex the arm. Because the clavicle is a superficial bone, it is more amenable to dissection which obviates a more difficult dissection of the scapular spine. The current study was undertaken with the objective of using the descending fibers of the trapezius muscle to evaluate their effect on shoulder movements.

\section{METHODS}

Patients with brachial plexus injuries who presented to the outpatient clinic of the Plastic Surgery Department were candidates for the study. A total of 41 patients were evaluated between 2009 and 2014, and 32 patients met inclusion criteria. All patients involved in this article agreed to have their facial pictures published and signed the consent form. The average age of the patients was 23.5 years with a range from 17 years to 42 years. Inclusion criteria were a supple shoulder, passive abduction more than $90^{\circ}$, good adductor muscles, trapezius muscle power more than $4+$ and an absence of locoregional injury. Exclusion criteria were dislocation or subluxation of the shoulder, a stiff shoulder, passive abduction less than $90^{\circ}$, weak adductor muscles, a weak trapezius muscle, the presence of a clavicular fracture and injury to the locoregional structures. Patients who had failed previous nerve reconstruction or nerve transfer and patients presenting 2 years or more following injury were the primary candidates for trapezius muscle transfer.

\section{Operative technique}

The patient was placed in the supine position with a pillow under the scapula and the neck turned to the opposite side. An incision was made on the anterior border of the trapezius muscle and extended down to the upper 4th of the humerus. The attachments of the upper descending fibers of the trapezius to the posterior border of the lateral 3rd of the clavicle and the attachment of the deltoid muscle to the anterior border of the clavicle were identified. The deltoid attachment was released and the attachment of the trapezius to the lateral clavicle was divided lateral to the coracoclavicular ligament [Figure 1a]. The deep surface of the clavicle was abraded with a bone rasp for bony union between the clavicle and the abraded humerus. The remaining fibers of the trapezius

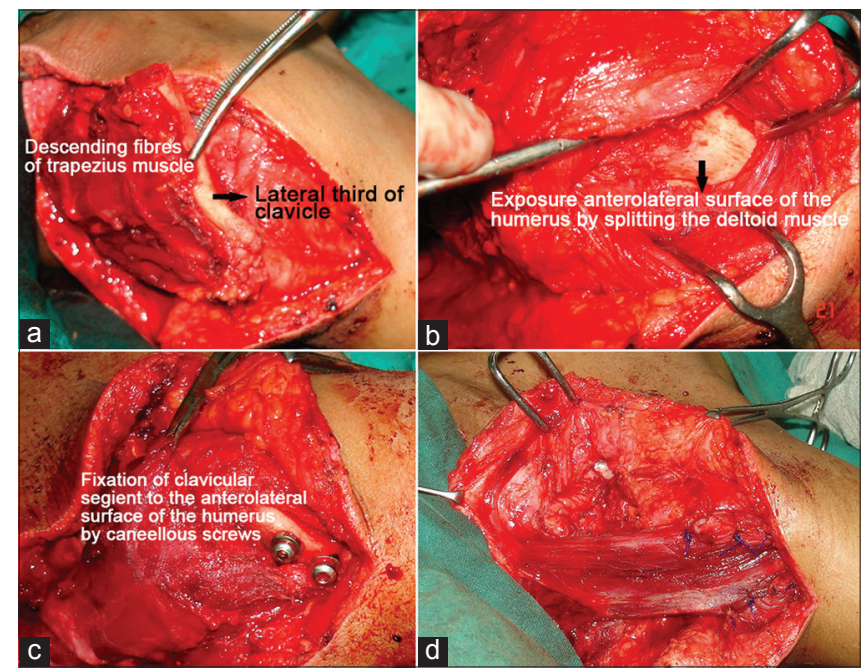

Figure 1: (a) Mobilisation of descending fibres of the trapezius muscle and their insertion on the posterior border of lateral third of clavicle; (b) exposure of anterolateral surface of humerus by splitting the deltoid muscle; (c) fixation of clavicular segment to the anterolateral surface of the humerus by cancellous screws; (d) suturing of deltoid with trapezius and bury the screws

to the acromion and spine of the scapula were left intact. The proximal humerus was exposed by splitting the deltoid longitudinally [Figure $1 \mathrm{~b}$ ] and slightly chiseled out to roughen the anterolateral surface of humerus. The rotator cuff was left untouched. With the humerus held in $90^{\circ}-100^{\circ}$ of abduction, the clavicular fragment with its trapezius insertion was transferred and fixed to the humerus with two $4 \mathrm{~mm}$ cancellous screws [Figure 1c]. The deltoid was then sutured over the trapezius with a polypropylene 1-0 suture to render strength to the trapezius and to bury the screws [Figure 1d]. The skin was closed over a suction drain. The arm was splinted in $90^{\circ}-100^{\circ}$ arm abduction. The mean operative time was $112 \mathrm{~min}$. Radiographs were taken on the 2nd postoperative day to assess the position of the screws and the clavicular fragment, and at 3 and 6 weeks to monitor any signs of union. The arm was immobilized for 6 weeks, but assisted and active exercises of the elbow, hand and fingers were initiated on postoperative day one. At one week, the splint was removed and a custom-made airplane splint was applied maintaining the position of abduction. Progressive passive adduction of the arm was started at that time, while active adduction and passive abduction in the supine position were initiated after 21 days. The same exercise was gradually done in the sitting position. After 6 weeks, active abduction and forward flexion were encouraged with splinting between exercises. The patient was evaluated monthly for 3 months and then every 3 months for one year.

\section{RESULTS}

In all the 32 patients, the transfer improved both the function and stability of the shoulder [Table 1]. The average increase in active abduction was from $7.5^{\circ}$ (range: $0^{\circ}-30^{\circ}$ ) to $85^{\circ}$ (range: $45^{\circ}-140^{\circ}$ ) at a mean follow-up of 8.25 months [Figures $2 \mathrm{a}$ and $\mathrm{b}$, Figure $3 \mathrm{a}$ and $\mathrm{b}$ ]. The range of improvement was from $35^{\circ}$ to $140^{\circ}$. Mean forward flexion improved from 


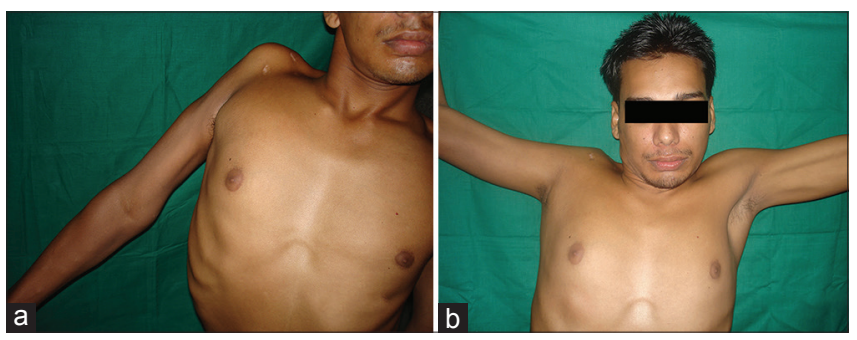

Figure 2: (a) Preoperative photograph of a 20-year-old male who presented 16 months after injury above the right clavicle; (b) postoperative photograph showing $100^{\circ}$ of active abduction of the right shoulder

$5.63^{\circ}$ (range: $0^{\circ}-15^{\circ}$ ) to $55.25^{\circ}$ (range: $40^{\circ}-90^{\circ}$ ), the range of improvement was from $25^{\circ}$ to $80^{\circ}$.

Muscle power plays a pivotal role in the day to day activities of a patient. Medical Research Council 4 was encouragingly found in 19 patients (59.38\%) after trapezius transfer [Table 2].

The patients' assessment of the results was excellent in 6 cases $(18.75 \%)$ when active abduction was more than $120^{\circ}$, good in 18 cases (56.25\%) when active abduction was $90^{\circ}-120^{\circ}$, fair in 5 cases (15.63\%) when active abduction was $60^{\circ}-90^{\circ}$, and poor in 3 cases (9.37\%) when active abduction was less than $60^{\circ}$ [Table 3 ].

\section{Complications}

Two patients were found to have a loose cancellous screw with abduction limited to $35^{\circ}$ and $45^{\circ}$, respectively. One patient required eventual removal of the loose screw. Flap necrosis at the suture line was observed in one patient and healed with conservative management.

\section{DISCUSSION}

Secondary surgery in brachial plexus palsy is often required for the restoration of shoulder movement ${ }^{[8]}$ and for the restoration of both analgesia and function. Because the shoulder joint is a large and proximal joint, it is essential for adequate function of distal joints of the upper limb. Local pedicled muscle transfer and glenohumeral arthrodesis remain the mainstay of treatment. With the recent advances in microsurgery, free muscle transfer is also possible. ${ }^{[2]}$

Arthrodesis of the shoulder has traditionally been an option in patients with instability secondary to a brachial plexus lesion. However, the surgical technique is difficult, lengthy, and there is no consensus regarding the ideal position for glenohumeral fixation. In addition, the rates of pseudoarthrosis, fracture, residual pain, repositioning of the limb, ${ }^{[9]}$ and irreversibility of the procedure are significant limiting factors. ${ }^{[10]}$ However, failure after muscle transfer may be salvaged by shoulder fusion. ${ }^{[1]}$ Microsurgery is more cumbersome, has a long learning curve, and tension adjustment is not reliable.

The trapezius muscle has previously been used as a donor muscle only with periosteum, ${ }^{[12]}$ which results in gradual stretching of the muscle and progressive loss of abduction, in trapezius muscle transfer with the spine
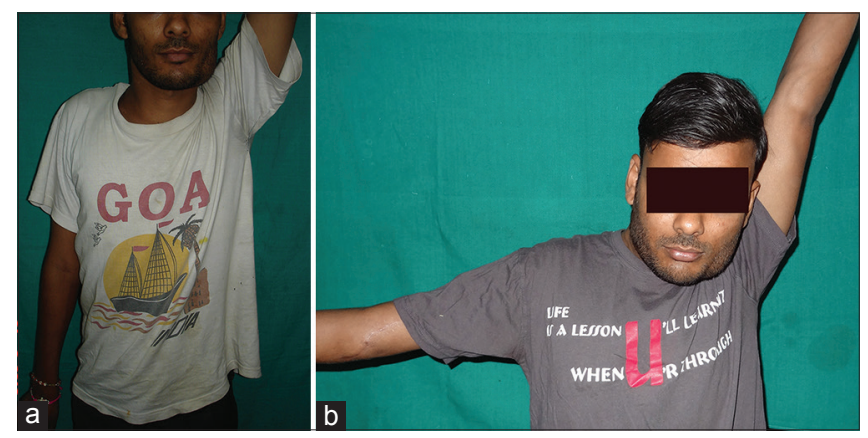

Figure 3: (a) Preoperative photograph of a 17-year-old male who had a failed nerve transfer on the right side; (b) postoperative photograph showing $90^{\circ}$ of active abduction of the right shoulder

Table 1: Results of modified trapezius transfer (32 patients)

Movements of Preoperative Range Postoperative Range shoulder

\begin{tabular}{lcccc}
\hline Abduction $\left({ }^{\circ}\right)$ & 7.5 & $0-30$ & 85 & $45-140$ \\
Forward flexion $\left({ }^{\circ}\right)$ & 5.63 & $0-15$ & 55.25 & $40-90$ \\
\hline
\end{tabular}

Mean follow-up 8.25 months (6.5-12 months)

Table 2: Muscle power after transfer (MRC scale)

\begin{tabular}{lc}
\hline MRC grade & Number of patients (\%) \\
\hline 4 & $19(59.38)$ \\
$2-3$ & $10(31.25)$ \\
$0-1$ & $3(9.37)$ \\
\hline
\end{tabular}

MRC: Medical Research Council

Table 3: Satisfaction level of patients and clinical correlation

\begin{tabular}{lcc}
$\begin{array}{l}\text { Subjective opinion } \\
\text { of patients }\end{array}$ & $\begin{array}{c}\text { Number of } \\
\text { patients }(\%)\end{array}$ & $\begin{array}{c}\text { Range of abduction which } \\
\text { satisfied the patients }\left(^{\circ}\right)\end{array}$ \\
\hline Excellent & $6(18.75)$ & $>120$ \\
Good & $18(56.25)$ & $90-120$ \\
Fair & $5(15.63)$ & $60-90$ \\
Poor & $3(9.37)$ & $<60$ \\
\hline
\end{tabular}

of the scapula and acromion, ${ }^{[4]}$ and in mobilization of the upper and middle trapezius muscle with the clavicle, acromion and scapular spine. ${ }^{[5]}$ The latter two procedures involve extensive, deep and difficult dissection with sacrifice of a significant amount of muscle and bone.

In the technique presented in this paper, only the upper fibers with the lateral clavicle were dissected with good results.

Using Saha's technique, Aziz et al. ${ }^{[13]}$ noted that there was a gain in the abduction of $45.4^{\circ}$ following transfer of the acromioclavicular segment. Using the same procedure, Kotwal et al..$^{[14]}$ achieved a gain of $60^{\circ}$ of abduction, although the mean level of abduction attained was not mentioned. Conversely, Ruhmann et al. ${ }^{[15]}$ achieved a mean abduction of only $39^{\circ}$ with a mean forward flexion of $44^{\circ}$. Severo et al..$^{[10]}$ obtained more encouraging results with a mean postoperative abduction of $75.8^{\circ}$ and flexion of $77^{\circ}$. On the contrary, Ragab and El-Sayaed ${ }^{[16]}$ achieved only $39^{\circ}$ of abduction and $32^{\circ}$ of flexion. Clearly, the functional 
outcome following transfer of the trapezius muscle varies considerably.

The current technique of using the upper descending fibers is easy, quick and reliable with reproducible results and a definite increase in shoulder stability and function. The mean level of abduction of $85^{\circ}$ and flexion of $55.2^{\circ}$ achieved was encouraging. In 3 of 32 patients, almost $140^{\circ}$ of abduction was obtained. In addition, patients were satisfied with fullness in the otherwise atrophic deltoid region, improved forward flexion, a more stable shoulder joint, and decreased heaviness of the upper limb.

Passive shoulder abduction of more than $90^{\circ}$ and strong adductors are important prerequisites, and an intensive physiotherapy program should be initiated prior to transfer in order to gain more passive abduction. If adequate abduction is not attained, shoulder arthrodesis is the last resort.

Scar tissue secondary to prior surgery renders the dissection challenging. The use of pillow under the shoulder is recommended to elevate the field of dissection. The pillow should be removed prior to fixation on the humerus lest the transfer be impossible and the incision sutured under tension.

Many patients have osteoporosis of the humerus secondary to disuse following injury to the brachial plexus, creating difficulty in fixation of the clavicle to the humerus. Adequate preparation of the undersurface of the clavicle and anterolateral surface of the humerus is very important, and washers with screws were used in the current study to overcome this problem. Serial radiographs at intervals have been discussed previously. Nonunion was not observed in any cases, although one screw required removal.

Postoperative function depends on the greatest possible tension in the transferred muscle. Proximal mobilization of the trapezius muscle is limited secondary to possible damage to the accessory nerve, which should be identified during dissection. Anterolateral fixation on the humerus is important to achieve forward flexion and internal rotation in addition to the abduction.

Drains should be left in place for one to three days following surgery to prevent late seroma formation and subsequent adhesion of the muscle.

In conclusion, transfer of the upper trapezius muscle with a clavicular segment for a flail shoulder can provide satisfactory function and stability with fewer complications.

\section{Declaration of patient consent}

The authors certify that they have obtained all appropriate patient consent forms. In the form the patient(s) has/have given his/her/their consent for his/her/their images and other clinical information to be reported in the journal. The patients understand that their names and initials will not be published and due efforts will be made to conceal their identity, but anonymity cannot be guaranteed.

\section{Financial support and sponsorship}

Nil.

\section{Conflicts of interest}

There are no conflicts of interest.

\section{REFERENCES}

I. Terzis JK, Barmpitsioti A. Secondary shoulder reconstruction in patients with brachial plexus injuries. J Plast Reconstr Aesthet Surg 201 I;64:843-53.

2. Chwei-Chin Chuang D. Functioning free muscle transplantation for brachial plexus injury. Clin Orthop Relat Res 1995;3 I4: I04-I I.

3. Elhassan B, Bishop A, Shin A, Spinner R. Shoulder tendon transfer options for adult patients with brachial plexus injury. J Hand Surg Am 20 I0;35: I I I I-9.

4. Bateman JE. The Shoulder and Environs. St. Louis: CV Mosby; 1955.

5. Saha AK. Surgery of the paralyzed and flail shoulder. Acta Orthop Scand 1967;Suppl 97:5-90.

6. Haas SL. Treatment of permanent paralysis of deltoid muscle. JAMA 1935;104:99-103.

7. Mayer L. Transplantation of the trapezius for paralysis of the abductors of the arm. J Bone Joint Surg 1927;9:4I 2-20.

8. Berger A, Brenner PD. Secondary surgery following brachial plexus injuries. Microsurgery 1995; 16:43-7.

9. Cofield RH, Briggs BT. Glenohumeral arthrodesis: operative and long-term functional results. J Bone Joint Surg Am 1979;61:668-77.

10. Severo AL, Maia PE, Lemos MB, Piluski PC, Lech OL, Fukushima WY. Transfer of the trapezius to the deltoid for the treatment of shoulder instability after lesions of the brachial plexus. Surg Sci 2013;4:459-63.

II. Karev A. Trapezius transfer for paralysis of the deltoid. J Hand Surg (Br) 1986; I I:8I-3.

12. Singh AK, Karki D. Modified trapezius transfer technique for restoration of shoulder abduction in brachial plexus injury. Indian J Plast Surg 2007; 40:39-48

13. Aziz W, Singer RM, Wolff TW. Transfer of the trapezius for flail shoulder after brachial plexus injury. J Bone Joint Surg Br 1990;72:70I-4.

14. Kotwal PP, Mittal R, Malhotra R. Trapezius Transfer for deltoid paralysis. J Bone Joint Surg $(\mathrm{Br})$ 1998;80:1 I 4-16.

15. Ruhmann O, Wirth CJ, Gossé F, Schmolke S. Trapezius transfer after brachial plexus palsy. J Bone Joint Surg Br 1998;80:109-13.

16. Ragab RK, El-Sayaed AM. Modified trapezius transfer in brachial plexus palsy. correlation of the surgical outcome with the muscle power. Bull Alexandria Fac Med 2008;44:621-7. 